\title{
Relationship between Intestinal Colonization of Bifidobacterium bifidum in Infants and the Presence of Exogenous and Endogenous Growth- Promoting Factors in Their Stools
}

\author{
S. HUDAULT, C. BRIDONNEAU, P. RAIBAUD, C. CHABANET, AND M. F. VIAL \\ Unité d'Ecologie et de Physiologie du Système Digestif [S. H., C. B., P. R.] and Laboratoire de Biométrie [C. C.], \\ Institut National de la Recherche Agronomique, Jouy-en-Josas, France; and Hôpital Antoine Béclère, Maternité, \\ Clamart, France [M. F. V.]
}

\begin{abstract}
The relationship between the intestinal colonization of a test strain of Bifidobacterium bifidum requiring human milk growth-promoting factors in vitro and the presence of growth-promoting factors either in the stools of human neonates or in their diet was investigated. Thirty-one infants were inoculated with a single dose of this strain within the first $8 \mathrm{~d}$ of life. Spores of a strictly thermophilic Bacillus admixed with the B. bifidum inoculum were used as transit marker, and the fecal population levels of both strain $B$. bifidum and the transit marker were recorded within $6 \mathrm{~d}$ after inoculation. Strain $B$. bifi$d u m$ was found in the predominant flora of six neonates. It was eliminated more quickly than the transit marker from the stools of 17 neonates. Its population remained at a low level in the remaining eight neonates. Amounts of $B$. bifidum growth-promoting factor in the infant stools were not significantly different whether they harbored strain $B$. bifidum at a high population level or not. Although these amounts were significantly higher in infants fed human milk containing $B$. bifidum growth-promoting factor than in infants fed formula milk without $B$. bifidum growthpromoting factor, strain $B$. bifidum became established in one of the 18 infants fed human milk and in five of the 13 formula-fed infants. No relationship could be found between the population levels of strain $B$. bifidum and those of facultatively anaerobic streptococci and enterobacteria already present on $\mathrm{d} 0$ and 1 . These results clearly show that no relationship exists between the intestinal colonization of $B$. bifidum and the amounts of exogenous or endogenous growth-promoting factors found in stools. (Pediatr Res 35: 696-700, 1994)
\end{abstract}

\section{Abbreviations}

GPF, growth-promoting factor

$B$ bGPF, B. bifidum growth-promoting factor

BHI, brain heart infusion

Bifidobacterium is one of the first strictly anaerobic bacterial genera that can colonize the digestive tract of the human newborn as soon as the end of the $1 \mathrm{st}$ wk of life $(1-3)$. Various in vitro growth promoters for Bifidobacterium strains, bifidus factors, have been found in human or animal milk (3-6). GPF of $B$. bifidum var. pennsylvanicus have been first detected by György

Received August 4, 1992; accepted January 24, 1994.

Correspondence: S. Hudault, UEPSD, Bat 440, CRJ INRA, 78352 Jouy-enJosas, France.
(7) in human milk and later in cow's milk $(8,9)$ and in fecal contents of germfree mice (10). In human milk, these factors were oligosaccharides (7) and glycopolypeptides (4). In cow's milk (8) and in fecal contents of germfree mice (10), these factors were identified as glycopeptides and mucins. GPF for other strains of Bifidobacterium have been studied less. Recently, Petschow and Talbott (9) showed that GPF for various Bifidobacterium species are both whey and casein fractions of human and cow's milk and that they are different and specific for each species of Bifidobacterium. They also showed later (11) that the protein and nonprotein nitrogen fraction of whey cow's milk contains growth promoters for strains of $B$. bifidum var. pennsylvanicus, $B$. infantis, $B$. longum, and $B$. breve. However, no reliable results exist about the stimulating role played by GPF on the in vivo establishment of Bifidobacterium strains. The predominance of bifidobacteria in the microflora of breast-fed infants has been associated with the presence of GPF found in human milk $(3,11,12)$. However, Simhon et al. (13) and Benno et al. (14) have shown that Bifidobacterium was as numerous in infants fed cow's milk as in breast-fed infants. In germfree mice fed several diets either containing GPF from human milk or not, we have shown that the establishment of a strain of $B$. bifidum (strain B536), which was dependent in vitro on human milk GPF, did not depend on the presence of these factors in the diet or in the cecum (15).

The aim of this work was to study whether a relationship exists between the establishment of a strain of $B$. bifidum inoculated to human infants and the presence of GPF either in the milk they received or in their fecal content. The strain of $B$. bifidum used was dependent in vitro on human milk GPF.

\section{MATERIALS AND METHODS}

Study group. Thirty-one human healthy infants born at the A. Béclère maternity hospital (Clamart, France) were chosen for this study. None of them or the mothers of the breast-fed infants received antibiotic therapy before or during the study.

Diets. Because this study focused on the relationship between the intestinal colonization of $B$. bifidum and the presence of dietary $B b G P F$, the infant diets were divided in two classes. Class 1 comprised milk without $B b G P F$, including various commercially available formula milk. It was given to 13 infants. Class 2 comprised milk with $B b G P F$, including breast milk or human milk from donors (Lactarium de Paris, Paris, France) supplemented or not with less than $50 \%$ of milk for premature infants. It was given to 18 infants; 12 infants received breast milk exclusively, and the remaining six received supplemented human milk.

Bacterial inoculation. Strain B536 of B. bifidum was kindly 
provided by C. Romond (Faculté de Pharmacie, Lille, France). It was isolated from stools of a healthy breast-fed infant and preserved by lyophilization. This strain was spontaneously gentamicin resistant and was dependent in vitro on human milk GPF as described further. Spores of a strictly thermophilic $B a-$ cillus subtilis strain were used as transit marker as previously described by Ducluzeau et al. (16). A stock suspension of B536 strain was prepared by centrifuging 24 -h cultures at $37^{\circ} \mathrm{C}$. The pellet was washed in sterile PBS and suspended in sterile water. It was admixed with the transit marker suspension washed in sterile water. The stock suspension of strain B536 and spores of transit marker was kept in liquid nitrogen until the end of the experiments. A single dose containing $5 \times 10^{8}$ viable cells of strain B536 and $5 \times 10^{8}$ spores of the transit marker was thawed just before oral administration to each infant between two meals. This experimental procedure was agreed to by the ethical committee of the hospital and by the parents of the infants.

Bacterial cultures. Strain B536 was grown in BHI broth (Difco Laboratories, Detroit, MI) containing $200 \mathrm{~g} / \mathrm{L}$ calf brain infusion, $250 \mathrm{~g} / \mathrm{L}$ beef heart infusion, $10 \mathrm{~g} / \mathrm{L}$ proteose peptone (Difco), 20 $\mathrm{g} / \mathrm{L}$ bacto-dextrose, $0.08 \mathrm{M} \mathrm{NaCl}, 14 \mathrm{mM}$ disodium phosphate, final $\mathrm{pH}$ 7.4. A suspension of $B$. subtilis spores was prepared by plating spores on agar medium for spores (MS) (17) containing $8 \mathrm{~g} / \mathrm{L}$ meat extract (Merck AG, Darmstadt, Germany), $2 \mathrm{~g} / \mathrm{L}$ yeast extract (Difco), $0.23 \mathrm{mM}$ manganese sulfate, $1 \mathrm{~g} / \mathrm{L}$ glucose, $10 \mathrm{~g} / \mathrm{L}$ bacto-agar (Difco), final pH 6.3, and aerobic incubation for $3 \mathrm{~d}$ at $56^{\circ} \mathrm{C}$.

Bacterial counts. Feces were collected at least three times: on the day of inoculation, on the Ist $\mathrm{d}$ after inoculation, and then one to three times between $3 \mathrm{~d}$ and $6 \mathrm{~d}$ after inoculation. Counts were performed on the feces within $4 \mathrm{~h}$ after their emission. Stools were diluted 10 -fold in liquid casein yeast extract (LCY) medium containing $2 \mathrm{~g} / \mathrm{L}$ casein enzymatic hydrolysate (USB Corp., Cleveland, OH), $0.08 \mathrm{M} \mathrm{NaCl}, 7.2 \mathrm{mM}$ sodium monophosphate, $2 \mathrm{~g} / \mathrm{L}$ yeast extract (Difco), and homogenized with an ultraturrax (Osi, Paris, France) in an anaerobic chamber. Because $B$. bifidum strain B536 was spontaneously resistant to gentamicin and sodium azide, a selective medium was prepared by using solid BHI medium (BHI broth admixed with $20 \mathrm{~g} / \mathrm{L}$ Bi-tek agar, Difco) supplemented with $50 \mathrm{mg} / \mathrm{L}$ of gentamicin sulfate (ICN Biomedicals, Orsay, France) and $0.03 \mathrm{~g} / \mathrm{L}$ of sodium azide (ICN). A 1-mL sample of adequate 10-fold dilution was admixed with $0.1 \mathrm{~mL}$ of a $3 \mathrm{~g} / \mathrm{L}$ of sodium azide solution and kept at $37^{\circ} \mathrm{C}$ for $5 \mathrm{~min}$. Then $0.1 \mathrm{~mL}$ was plated on the selective agar medium. Other strains of Bifidobacterium were enumerated by plating $0.1 \mathrm{~mL}$ of 10 -fold dilutions on de Man, Rogosa, and Sharp (MRS) medium (Difco) containing $10 \mathrm{~g} / \mathrm{L}$ bacto-proteose peptone, $10 \mathrm{~g} / \mathrm{L}$ bacto-beef extract, $5 \mathrm{~g} / \mathrm{L}$ bacto-yeast extract, 20 $\mathrm{g} / \mathrm{L}$ bacto-dextrose, $0.1 \%$ Tween $80,8.8 \mathrm{mM}$ ammonium citrate, $0.03 \mathrm{M}$ sodium acetate, $0.4 \mathrm{mM}$ magnesium sulfate, $0.3 \mathrm{mM}$ manganese sulfate, $11.5 \mathrm{mM}$ dipotassium sulfate, $22 \mathrm{~g} / \mathrm{L}$ agar (Difco), final pH 5.4. Because B. bifidum strain B536 also grows on MRS medium, clones of Bifidobacterium were isolated from the highest dilutions on MRS medium to check their $B b G P F$ requirements. They were assumed to be other Bifidobacterium, different from the inoculated strain, provided that their $B b G P F$ requirements were different from those of the $B$. bifidum strain in a specific medium as described further.

Total counts of enterobacteria were obtained on deoxycholate citrate agar (DCA) medium (Difco) containing $10 \mathrm{~g} / \mathrm{L}$ bactopeptone, $10 \mathrm{~g} / \mathrm{L}$ lactose, $1 \mathrm{~g} / \mathrm{L}$ sodium deoxycholate, $0.08 \mathrm{M}$ $\mathrm{NaCl}, 11.5 \mathrm{mM}$ dipotassic phosphate, $1 \mathrm{~g} / \mathrm{L}$ ferric citrate, 3.4 $\mathrm{mM}$ sodium citrate, $0.003 \mathrm{~g} / \mathrm{L}$ neutral red, $\mathrm{pH} 7.0$. Counts of streptococci were performed on an agar medium (18) containing $10 \mathrm{~g} / \mathrm{L}$ bacto-peptone (Difco), $10 \mathrm{~g} / \mathrm{L}$ bacto-tryptone (Difco), 10 $\mathrm{g} / \mathrm{L}$ yeast autolysate (Difco), $1 \mathrm{~g} / \mathrm{L}$ saccharose, $14 \mathrm{~g} / \mathrm{L}$ agar (Difco), final $\mathrm{pH} 7.7$, and $0.03 \mathrm{~g} / \mathrm{L}$ sodium azide with the procedure described for strain $\mathrm{B} 536$. Incubation at $37^{\circ} \mathrm{C}$ was performed in an anaerobic chamber for BHI-gentamicin-azide and MRS medium for $5 \mathrm{~d}$ and aerobically for streptococci and enterobacteria for $2 \mathrm{~d}$. Spores of $B$. subtilis were enumerated on MS medium incubated at $56^{\circ} \mathrm{C}$ for $48 \mathrm{~h}$ aerobically.

Determination of $B b G P F$ titer. Samples of milk from each mother, each donor (Lactarium), each milk for preterm infant, or each formula milk were stored once during the study at $4^{\circ} \mathrm{C}$ before dilution for $B b G P F$ determination. Feces from each infant were diluted 4-fold and centrifuged at $35000 \times g$ for $30 \mathrm{~min}$. Supernatants were stored at $-18^{\circ} \mathrm{C}$. Each sample was serially diluted 2-fold to 1/256. Serial 2-fold dilutions of solution of $\mathrm{N}$ acetylglucosamine at $50 \mathrm{~g} / \mathrm{L}$ of cow's and human milk were included in each test as references.

To determine $B b G P F$ titer, we used aliquots of $0.1 \mathrm{~mL}$ of a fresh culture $\left(18 \mathrm{~h}\right.$ at $\left.37^{\circ} \mathrm{C}\right)$ of strain B536 to inoculate five tubes of $10 \mathrm{~mL}$ of BHI broth. After incubation for $24 \mathrm{~h}$ at $37^{\circ} \mathrm{C}$ in an anaerobic chamber, the cultures were centrifuged at $2000 \times g$ for $15 \mathrm{~min}$. The pellet was washed in 4-fold diluted modified Ringer cysteine solution and suspended in liquid Garches medium to obtain an absorbance of 1.3 at $630 \mathrm{~nm}$ as described by Neut et al. (19). Solid Garches medium was inoculated at $5 \%$ with the bacterial suspension. The inoculated medium was plated, and wells were stamped out. Aliquots of $50 \mu \mathrm{L}$ of serially diluted samples were added to the wells. Plates were then incubated at $37^{\circ} \mathrm{C}$ for $3 \mathrm{~d}$ in an anaerobic chamber. The same procedure was used for the other Bifidobacterium strains to distinguish them from $B$. bifidum. Under the conditions described above, the $B$. bifidum B536 strain grows exclusively around wells of human milk and $N$-acetylglucosamine; those not exhibiting such requirements were considered to be other $B i f i$ dobacterium strains.

$B b G P F$ titer was given as the $\log _{10}$ of the inverse of the last positive dilution, i.e. the dilution for which one can measure the diameter of the zone of growth. Determinations were performed twice.

Statistical analysis. Bacterial counts and BbGPF titers were compared with the $t$ test of the analysis of variance. A correspondence analysis was also performed with various microbial and individual characteristics recorded for each of the 31 infants. Microbial parameters were the population levels (expressed in $\log _{10} / \mathrm{g}$ of fresh stools) of $B$. bifidum and of the other Bifidobacterium on $\mathrm{d} 1$ and 2 and between 3 and $6 \mathrm{~d}$ after inoculation and those of enterobacteria and streptococci on $\mathrm{d} 0$ and 1 and 2 $\mathrm{d}$ after inoculation. Population levels of Bifidobacterium, streptococci, and enterobacteria were defined as follows: level $1,<4.0$, $<8.0$, and $<6.0$, respectively; level $2,4.0-7.5,8.0-9.5$, and 6.0 9.5 , respectively; and level $3,>7.5,>9.5$, and $>9.5$, respectively. Individual characteristics were birth weight, mode of delivery, feeding, gestational age, and amounts of $B b G P F$ in the feces on $\mathrm{d} 0$ and 1 and 2 or $3 \mathrm{~d}$ after $B$. bifidum inoculation. A classification according to these characteristics was set out in a contingency table with the population levels of $B$. bifidum strain in the columns, fecal $B b G P F$, and other microbiological parameters in the lines. Individual parameters were considered as supplementary variables and were projected on the first plan defined by axis 1 and axis 2 .

\section{RESULTS}

Evolution of $B$. bifidum strain and transit marker fecal counts. Three groups of infants $(A, B$, and $C)$ were distinguished by comparing the individual fecal counts of the test strain of $B$. bifidum and those of the transit marker (Table 1). B. bifidum became established in group A (6 of the 31 infants) because its population level largely outnumbered that of the transit marker between 3 to $6 \mathrm{~d}$ after inoculation. By contrast, B. bifidum was eliminated from infant stools at the same rate as the transit marker in group $C$ ( 17 of 31 infants). B. bifidum became established at a low level in the remaining eight neonates of group B because it was significantly higher than that in group $C$ and significantly lower than that of group $\mathrm{A}$, indicating that $\operatorname{strain} B$. bifidum did not belong to the predominant flora of these infants. 
Table 1. Evolution of population level of inoculated transit marker and B. bifidum strain in infants and distribution of infants according to final population level of inoculated B. bifidum strain in stools

\begin{tabular}{|c|c|c|c|c|c|c|}
\hline \multirow{3}{*}{$\begin{array}{l}\text { Days after } \\
\text { inoculation }\end{array}$} & \multicolumn{6}{|c|}{ Infant groups (no. of infants) } \\
\hline & \multicolumn{2}{|c|}{$\begin{array}{c}\text { A } \\
(n=6)\end{array}$} & \multicolumn{2}{|c|}{$\begin{array}{c}\mathrm{B} \\
(n=8)\end{array}$} & \multicolumn{2}{|c|}{$\begin{array}{c}C \\
(n=17)\end{array}$} \\
\hline & $\mathrm{TM}^{*}$ & $\mathbf{B b}^{*}$ & TM & $\mathrm{Bb}$ & TM & $\mathrm{Bb}$ \\
\hline 1 & $6.5 \pm 0.5$ & $6.2 \pm 0.9$ & $7.2 \pm 0.2$ & $5.6 \pm 0.6$ & $6.3 \pm 0.4$ & $5.6 \pm 0.7$ \\
\hline 2 & $5.1 \pm 1$ & $5.2 \pm 1.3 \dagger$ & $6.1 \pm 0.7$ & $5.2 \pm 0.7 \dagger$ & $5.4 \pm 0.4$ & $3.9 \pm 0.1 \dagger$ \\
\hline $3-6$ & $2.9 \pm 0.4$ & $8.5 \pm 0.3 \ddagger$ & $3.4 \pm 0.5$ & $6.0 \pm 0.1 \ddagger$ & $3.7 \pm 0.4$ & $3.9 \pm 0.0 \ddagger$ \\
\hline
\end{tabular}

\footnotetext{
* $\log _{10}$ number of spores of transit marker (TM) or of $B$. bifidum $(\mathrm{Bb})$ per gram of feces. $B$. bifidum counts were significantly different between group $C$ and groups $A$ and $B(p<0.01$ on $d 2$ after inoculation, and $p<0.001$ on $\mathrm{d} 3$ to 6 ) and between group $B$ and groups $A$ and $C$ on $d 3$ to 6 $(p<0.001)$.

$\dagger p<0.01$.

$\ddagger p<0.001$.
}

Table 2. Distribution of individual characteristics in three groups of neonates

\begin{tabular}{lccc}
\hline & \multicolumn{3}{c}{ Infant groups (no. of infants) } \\
\cline { 2 - 4 } $\begin{array}{c}\text { Individual } \\
\text { characteristics }\end{array}$ & $\begin{array}{c}\mathrm{A} \\
(n=6)\end{array}$ & $\begin{array}{c}\mathrm{B} \\
(n=8)\end{array}$ & $\begin{array}{c}\mathrm{C} \\
(n=17)\end{array}$ \\
\hline Delivery & & & \\
$\quad$ Cesarean & 2 & 5 & 7 \\
$\quad$ Normal & 4 & 3 & 11 \\
Gestational age (wk) & & & \\
$34-37$ & 2 & 3 & 4 \\
$37-39$ & 1 & 4 & 8 \\
$39-43$ & 3 & 1 & 5 \\
Birth weight (g) & & & \\
1500-2450 & 2 & 3 & 4 \\
$2450-3500$ & 4 & 4 & 8 \\
$3500-4040$ & 0 & 1 & 5 \\
Milk without $B b$ GPF $\dagger$ & 5 & 3 & 5 \\
Milk with $B p$ GPF $\dagger$ & 1 & 5 & 12 \\
Day of inoculation & & & \\
1 to 2 & 4 & 7 & 15 \\
5 to 8 & 2 & 1 & 2 \\
\hline
\end{tabular}

* For description of groups of infants, see Table 1.

$\uparrow$ Milk with $B b G P F$ includes milk containing breast milk or human milk from donors supplemented or not with less than $50 \%$ of milk for premature infants; milk without $B b G P F$ includes various commercially available formula milk.

Table 2 gives some individual characteristics of neonates from each group, including ranges of birth weight and gestational age, mode of delivery, and age on the day of inoculation. Notably, only one of six infants from group A received milk with $B b G P F$ versus 12 of 17 in group $C$ infants. The population level of $B$. bifidum was not significantly different on the 1 st $\mathrm{d}$ after inoculation between the three groups of infants and was smaller than the population of the transit marker, indicating a partial destruction of the inoculum.

Fecal amounts of BbGPF according to population level of $B$. bifidum, infant diet, and sampling day. BbGPF titers in 12 samples of mother milk and in six samples of human milk from donors ingested by the neonates ranged from 0.9 to 2.7 , whereas those of the 13 formula milk samples ranged from 0 to 0.6 . Table 3 shows that $B b G P F$ titers were not significantly different in the three groups (A, B, and C) whatever the day after inoculation. A significant decrease was observed on $\mathrm{d} 2$ and between 3 to $6 \mathrm{~d}$ in stools of infants fed milk without $B b G P F$ as compared with infants fed milk with these factors.

Relationship between fecal population levels of B. bifidum and those of other bacterial groups according to sampling day. Because the test strain of $B$. bifidum also grew on MRS medium, the $B b G P F$ requirement was determined for 88 clones isolated from the highest fecal dilutions on MRS medium on $\mathrm{d} 1$ and 2 and 3 to $6 \mathrm{~d}$ after inoculation to verify the presence of other strains of Bifidobacterium in the infant stools. Fifty of 88 clones tested did not require $B b G P F$, thus being other Bifidobacterium different from the test strain. As shown in Table 4, bifidobacteria growing in MRS medium but without $B b G P F$ requirements were absent in all but two samples on the day of inoculation of $B$. bifidum. However, their population level was higher in stools of group A (8.4 \pm 0.8$)$ than in groups B $(5.7 \pm 0.7)$ and C (5.8 \pm 0.6 ) on $\mathrm{d} 3$ to 6 after inoculation (Table 4). As shown by comparison of Table 1 and Table 4 , the population levels of other Bifidobacterium were higher than those of $B$. bifidum in group $A$ on $d 2$ after inoculation $(7.8 \pm 1.5$ versus $5.2 \pm 1.3)$ and in group $C$ on $d 2$ and $d 3$ to 6 after inoculation ( $5.6 \pm 0.1$ versus $3.9 \pm 0.9$ on $\mathrm{d} 2$ and $5.8 \pm 0.6$ versus $3.9 \pm 0.0$ on $\mathrm{d} 3$ to $6, p<$ 0.01 and $p<0.001$, respectively).

Facultatively anaerobic streptococci and enterobacteria were still present at rather high levels on the day of inoculation, and their population levels increased during the subsequent days with large variations between individuals for enterobacteria on $\mathrm{d} 3$ to 6. No significant differences were observed between the three groups of infants.

Correlation between fecal population levels of B. bifidum and microbial and individual characteristics of infants. Correspondence analysis (data not shown) shows that no correlation existed between the population size of strain $B$. bifidum and the birth weight, the mode of delivery, or the gestational age. However, a positive correlation existed between the population size of strain $B$. bifidum and formula milk feeding and the inoculation on $\mathrm{d} 5$ to 8 after birth. This finding indicates that colonization of $B$. bifidum was better when inoculated later in life and in formulafed infants. It also confirms that no correlation existed between the population size of strain $B$. bifidum and the amounts of exogenous or endogenous $B b \mathrm{GPF}$ and with the population size of streptococci or enterobacteria, whereas a positive correlation did exist between the population size of the other bifidobacteria.

\section{DISCUSSION}

Spores of a thermophilic Bacillus strain admixed with the $B$. bifidum inoculum were given orally to all infants. This procedure was used to make sure that the strain had been ingested by the neonates and to compare the digestive transit time of the inoculated infants. Three groups of neonates were distinguished by comparing the daily fecal counts of both spores of the transit marker and $B$. bifidum strain for each infant. In group A (six of the 31 inoculated infants), $B$. bifidum strain remained in the predominant fecal flora 3 to $6 \mathrm{~d}$ after inoculation even though only one infant ingested milk with $B b G P F$. B. bifidum strain was eliminated or remained at a low population level in groups B and $\mathrm{C}$, i.e. in 25 of the inoculated infants, whatever the nature of the milk. These results clearly show that the presence of $B b G P F$ in the diet alone does not ensure colonization of infants by the test strain of $B$. bifidum. Moreover, $B b G P F$, as determined by the same in vitro method as for milk, were present in stools of all inoculated infants. The unexpected absence of $B$. bifidum 
Table 3. Amounts of BbGPF in feces of infants according to population level of B. bifidum, sampling day, and diet

\begin{tabular}{|c|c|c|c|c|c|}
\hline \multirow[b]{3}{*}{$\begin{array}{l}\text { Days after } \\
\text { inoculation }\end{array}$} & \multicolumn{5}{|c|}{$B b G P F$ titers in feces* } \\
\hline & \multicolumn{3}{|c|}{$\begin{array}{l}\text { Feces of infant groups } \\
\text { (no. of infants) } \dagger\end{array}$} & \multicolumn{2}{|c|}{$\begin{array}{l}\text { Feces of infants fed on milk } \\
\text { (no. of infants) }\end{array}$} \\
\hline & $\begin{array}{c}\mathrm{A} \\
(n=6)\end{array}$ & $\begin{array}{c}\text { B } \\
(n=8)\end{array}$ & $\begin{array}{c}\mathrm{C} \\
(n=17)\end{array}$ & $\begin{array}{l}\text { With } B b G \text { GF } \\
(n=18) \ddagger\end{array}$ & $\begin{array}{l}\text { Without } B b G \mathrm{GF} \\
\quad(n=13) \ddagger\end{array}$ \\
\hline 0 & $1.8 \pm 0.3$ & $2.2 \pm 0.2$ & $2.0 \pm 0.3$ & $1.9 \pm 0.2$ & $1.8 \pm 0.2$ \\
\hline 1 & $2.1 \pm 0.2$ & $1.9 \pm 0.2$ & $1.8 \pm 0.2$ & $1.9 \pm 0.2$ & $1.8 \pm 0.2$ \\
\hline 2 & $1.8 \pm 0.2$ & ND\$ & $1.9 \pm 0.2$ & $2.2 \pm 0.1$ & $1.4 \pm 0.1 \|$ \\
\hline $3-6$ & $1.7 \pm 0.3$ & $1.7 \pm 0.3$ & $2.1 \pm 0.2$ & $2.2 \pm 0.1$ & $1.4 \pm 0.2 \|$ \\
\hline
\end{tabular}

* $B b$ GPF titer is the $\log _{10}$ of the inverse of the last positive dilution, i.e. the dilution for which one can measure the diameter of the zone of growth (mean and SEM).

† For description of infant groups, see Table 1.

$\ddagger$ See Table 2.

$\S$ Not done.

$\| p<0.001$.

Table 4. Population levels of noninoculated Bifidobacterium and other bacterial genera in three infant groups according to sampling day

\begin{tabular}{|c|c|c|c|c|c|}
\hline \multirow[b]{2}{*}{ Bacterial genera } & \multirow{2}{*}{$\begin{array}{c}\text { Infant group } \\
\text { (no. of infants) }\end{array}$} & \multicolumn{4}{|c|}{ Days after inoculation $\dagger$} \\
\hline & & 0 & 1 & 2 & $3-6$ \\
\hline \multirow[t]{3}{*}{ Bifidobacteria } & $A(6)$ & $<2.0$ & $7.2(0.7)$ & $7.8(1.5)$ & $8.4(0.8) \ddagger$ \\
\hline & B (8) & $<2.0 \S$ & $6.5(0.7)$ & $6.6(1.8)$ & $5.7(0.7)$ \\
\hline & $C(17)$ & $<2.0 \S$ & $5.8(0.5)$ & $5.6(0.9)$ & $5.8(0.6)$ \\
\hline \multirow[t]{3}{*}{ Streptococci } & $A(6)$ & $8(0.8)$ & $8.8(0.4)$ & $8.5(0.6)$ & $9.6(0.3)$ \\
\hline & B (8) & $7.5(0.6)$ & $9(0.4)$ & $8.7(0.3)$ & $9.4(0.3)$ \\
\hline & $C(17)$ & $6.5(0.5)$ & $8.5(0.2)$ & $8.6(0.3)$ & $8.8(0.5)$ \\
\hline \multirow[t]{3}{*}{ Enterobacteria } & $A(6)$ & $7.5(1.0)$ & $8.0(1.1)$ & $7.6(1.4)$ & $7.4(2.2)$ \\
\hline & B (8) & $7.2(0.8)$ & $8.8(0.6)$ & $7.9(1.5)$ & $8.5(1.3)$ \\
\hline & $C(17)$ & $7.7(0.6)$ & $9(0.4)$ & $9.2(0.5)$ & $9.8(0.1)$ \\
\hline
\end{tabular}

* For description see Table 1.

+ Values are mean (SEM) $\log _{10}$ no. of bacteria/g of feces.

$\ddagger$ Different from groups B and C at d 3-6 after inoculation at $p<0.05$.

$\S$ True for all but one infant who harbored $9.0\left(\log _{10}\right)$ bifidobacteria/g of feces; these Bifidobacterium have no $B b G P F$ requirements and grow on MRS medium.

strain in the predominant flora of 25 of 31 infants remains unexplained. It might be assumed that $B$. bifidum strain, although isolated from the predominant flora of a healthy infant and preserved by lyophilisation, was a noncompetitive strain. However, we have observed that a significant correlation exists between the fecal counts of the $B$. bifidum strain and those of the other Bifidobacterium. Thus, the absence of Bifidobacterium in the predominant flora seems to be related more to the bacterial genus than to the strain used. Because the kinetics of elimination of the transit marker did not differ significantly from one infant to another, one cannot suppose that the individual differences observed in the population size of $B$. bifidum strain were related to individual differences in their digestive transit time. An alternative to explain these results would be that members of the predominant fecal flora of the infants exerted an antagonism or a synergy on $B$. bifidum. In our study, streptococci and enterobacteria represented the predominant bacterial strains, and no relationship between their fecal counts and those of $B$. bifidum was observed. Nevertheless, some specific strains of streptococci or enterobacteria, for instance strains producing trypsin-resistant bacteriocin having a broad activity spectrum, might be responsible for the lack of colonization of $B$. bifidum strain. As a matter of fact, we have previously demonstrated that a strain of Escherichia coli was able to eliminate a strain of Lactobacillus casei from the digestive tract of a gnotobiotic infant (20). However, the mechanism of this interaction has not been explained yet. Another hypothesis could be that some endogenous substances are bacteriostatic or bactericidal for the test strain of $B$. bifidum and other bifidobacteria. Such substances could be absent in infants of group A while present in groups B and C. Otherwise, such inhibitory substances could be produced by some "pioneer" strains, i.e. strains first colonizing the intestinal tract, in groups $B$ and $C$ but not in group $A$. It might be also suggested that some exogenous or endogenous growth factors other than $B b G P F$ were present in infant group $A$, leading to a prompt intestinal colonization by the bifidobacteria. Such still unknown growth factors could either be only present in the various milk given to infant group A or be produced by the "pioneer" strains from endogenous secretions.

Whatever the mechanisms involved, our results demonstrate that the $B$. bifidum GPF, as determined by in vitro experiments, do not play any role in the intestinal colonization of the inoculated $B$. bifidum strain. This finding shows that mechanisms demonstrated under in vitro conditions may not occur in the intestinal tract. Our results also demonstrate that inoculation of a strain, even in high number, does not necessary lead to its intestinal colonization. The factors responsible for the intestinal colonization of a given bacterial strain coming from either the environment or inoculated have still to be determined. This represents a serious limitation in the control of the colonization of beneficial bacterial strains in the intestine of neonates.

\section{REFERENCES}

1. Stark PL, Lee A 1985 The microbial ecology of the large bowel of breast fed and formula fed infants during the first year of life. J Med Microbiol 15:89and 103

2. Moreau MC. Thomasson M. Ducluzeau R, Raibaud P 1986 Cinétique d'établissement de la microflore digestive chez le nouveau-né humain en fonction de la nature du lait. Reprod Nutr Dev 26:745-753

3. Beerens H. Romond C. Neut C 1980 Influence of breast-feeding on the bifid flora of the newborn intestine. Am J Clin Nutr 33:2434-2439

4. Bezkorovainy A. Grohlich D. Nichols JH 1979 Isolation of a glycopolypeptide fraction with Lactohacillus hifidus subspecies pennsylvanicus growth-pro- 
moting activity from whole human milk casein. Am J Clin Nutr 32:14281432

5. Bezkorovainy A, Topouzian N 1981 Bifidobacterium bifidus var. pennsylvanicus growth promoting activity of human milk casein and its derivatives. Int J Biochem 13:585-590

6. Romond C, Beerens H, Neut C, Montreuil J 1980 Contribution à la maternisation des laits: influence in vitro du lait maternel, du lait de vache et de laits maternisés sur la croissance de Bifidobacterium. Ann Microbiol (Inst Pasteur) 131A:309-314

7. György P 1954 A hitherto unrecognized biochemical difference between human milk and cow's milk. Arch Biochem Biophys 48:193-201

8. Kehagias C, Jao YC, Mikolajcik EM, Hansen PMT 1977 Growth response of Bifidobacterium bifidum to a hydrolytic product isolated from bovine casein. J Food Sci 42:146-150

9. Petschow BW, Talbott RD 1990 Growth promotion of Bifidobacterium species by whey and casein fractions from human and bovine milk. J Clin Microbiol 28:287-292

10. Romond MB, Romond C, Beerens H, Bourlioux P 1986 Fecal bifidus factors of the germfree mice. In: Dubourguier HC, Albagnac G, Montreuil J, Romond C, Sautière P, Guillaume J (eds) Biology of Anaerobic Bacteria. Elsevier Science Publishers B.V., Amsterdam, pp 69-74

11. Petschow BR, Talbott RD 1991 Response of Bifidobacterium species to growth promoters in human milk and cow's milk. Pediatr Res 29:208-213

12. Bullen CL, Tearle PV, Stewart MG 1977 The effect of "humanised" milks and supplemented breast-feeding on the faecal flora of infants. J Med Microbiol supplemented

13. Simhon A, Douglas JR, Drasar BS, Soothill JF 1982 Effect of feeding on infants' faecal flora. Arch Dis Child 57:54-58

14. Benno Y, Sawada K, Mitsuoka T 1984 The intestinal microflora of infants: composition of fecal flora in breast-fed and bottle-fed infants. Microbio Immunol 28:975-986

15. Hudault S, Bridonneau C. Ducluzeau R, Raibaud P 1991 Effect of bovine or human milk on the establishment of Bifidobacterium bifidum in gnotobiotic mice fed cow or human milk; equilibrium with some other bacteria from the human neonatal microflora. Microbiol Ecol Human Health Dis 4:1-8

16. Ducluzeau R, Bellier M, Raibaud P 1970 Transit digestif de divers inoculums bactériens introduits "per os" chez des souris axéniques et "holoxéniques" (conventionnelles): effet de la microflore du tractus gastro-intestinal. $\mathrm{Zbl}$ Bakt I Orig 213:533-548

17. Contrepois M, Gouet $P 1969$ Utilisation d'une technique microbiologique pour la mesure de la vitesse du transit des microparticules dans le tractus digestif des ruminants. C R Acad Sci Paris 268:1757-1759

18. Raibaud P, Galpin JVG, Ducluzeau R, Mocquot G 1967 Studies on the bacterial flora of the alimentary tract of pigs. II. Streptococci: selective enumeration and differentiation of the dominant group. J Appl Bacteriol 24:285-306

19. Neut C. Romond C, Beerens H, Catteau M 1981 A rapid screening test, in vitro, for bifidus growth factors. In: Adam A, Ers P, Pijck J (eds) Current Concepts in Microbiology. Elsevier, Amsterdam, pp 67-76

20. Hudault S, Ducluzeau R, Dubos F, Raibaud P, Ghnassia JC, Griscelli C 1976 Elimination du tube digestif d'un enfant "gnotoxénique" d'une souche de Lactobacillus casei, issue d'une préparation commerciale: démonstration chez des souris "gnotoxéniques" du rôle antagoniste d'une souche de Escherichia coli d'origine humaine. Ann Microbiol Inst Past 127B:75-82 